\title{
Angiomyofibroblastoma of the vulva: A case report with literature review
}

\author{
Jung Ho Park ${ }^{1}$, Mi Kyung Shin ${ }^{2}$, Maria Lee ${ }^{3}$, Sung Taek Park ${ }^{4}$, Sung-Ho Park ${ }^{4}$, Hong-Bae Kim ${ }^{4}$ \\ ${ }^{1}$ Hallym University Collage of Medicine, Chuncheon, Korea \\ ${ }^{2}$ Department of Pathology, Hallym University Kangnam Sacred Heart Hospital, Seoul, Korea \\ ${ }^{3}$ Department of Obstetrics \& Gynecology, Hallym University Kangdong Sacred Heart Hospital, Seoul, Korea \\ ${ }^{4}$ Department of Obstetrics \& Gynecology, Hallym University Kangnam Sacred Heart Hospital, Seoul, Korea; \\ *Corresponding Author: Parkst96@,naver.com
}

Received 17 March 2013; revised 20 April 2013; accepted 15 May 2013

Copyright (C) 2013 Jung Ho Park et al. This is an open access article distributed under the Creative Commons Attribution License, which permits unrestricted use, distribution, and reproduction in any medium, provided the original work is properly cited.

\begin{abstract}
Angiomyofibroblastoma (AMF) is a rare kind of soft tissue tumor that occurs predominantly in the vulva. Due to their location, clinicians often confuse AMF with Bartholin's cyst or perineal hernia. Radiological evaluation is performed to rule out perineal hernia and invasive neoplasm. Like other benign mesenchymal tumors of vulva, AMF shows indolent behavior and rarely recurs after complete surgical excision.
\end{abstract}

Keywords: Angiomyofibroblastoma; Vulvar Neoplasm

\section{INTRODUCTION}

Angiomyofibroblastoma (AMF) was first described by Fletcher et al. in 1992 [1]. The disease is a rare mesenchymal tumor that arises in the female genital tract. The tumor is usually asymptomatic, slow-growing and discovered as a small mass. It is cured by complete surgical excision and is unlikely to recur. However, it should be differentiated from aggressive angiomyxoma (AAM) histologically.

\section{CASE PRESENTATION}

A 51-year-old Korean woman, gravid 5 para 3, complained of a painless mass at the right vulva for a year. She had a history of treated pulmonary tuberculosis 30 years ago. She had regular menstrual cycles. Pelvic exam revealed a soft, non-tender mass in the anterior aspect of right labia majora. There was no palpable node in the inguinal area. There was no change on the overlying skin. An ultrasonography revealed a slightly hypoechogenic lesion of $21 \mathrm{~mm}$ with posterior shadowing. Assumed to be a vulvar cystic mass, the tumor was locally excised.

The mass grossly resembled herniated intestine, but it was easily separated from surrounding tissues (Figure 1). The specimen was grossly well-circumscribed, red-pale in color and measured $2.5 \times 1.5 \times 0.8 \mathrm{~cm}$. Histologically, alternating hypercellular and hypocellular edematous areas were seen, and the plump stromal cells clustered around abundant blood vessels (Figure 2). Immunohistochemical profiles were strongly positive for vimentin, estrogen receptor and partly positive for desmin. It was negative for cytokeratin and HMB45.

The resection margin was negative for tumor cells and there was no evidence of recurrence during two months' follow up.

\section{DISCUSSION}

AMF is a benign mesenchymal origin tumor that is predominantly found in vulva, although it can arise in other sites such as vagina, cervix, or retroperitoneum. In Korean literature, total 13 cases were reported since 1995 (Table 1). These cases were women aged from 21 to
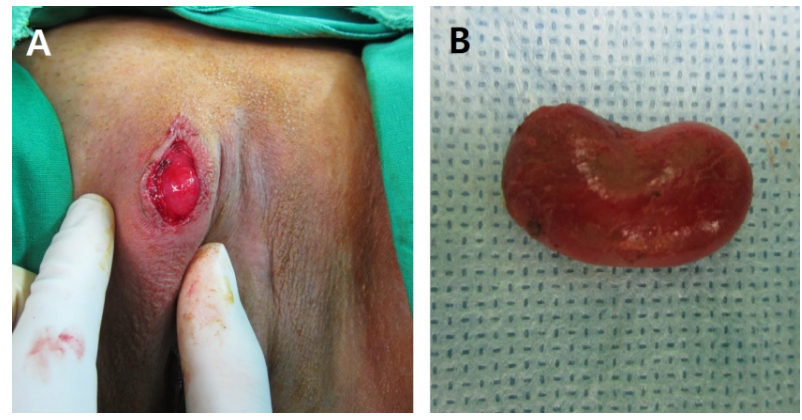

Figure 1. (A) The $2.5 \times 1.5 \mathrm{~cm}$ mass at right labia majora. (B) The excised tumor shows well circumscribed surface and red color. 


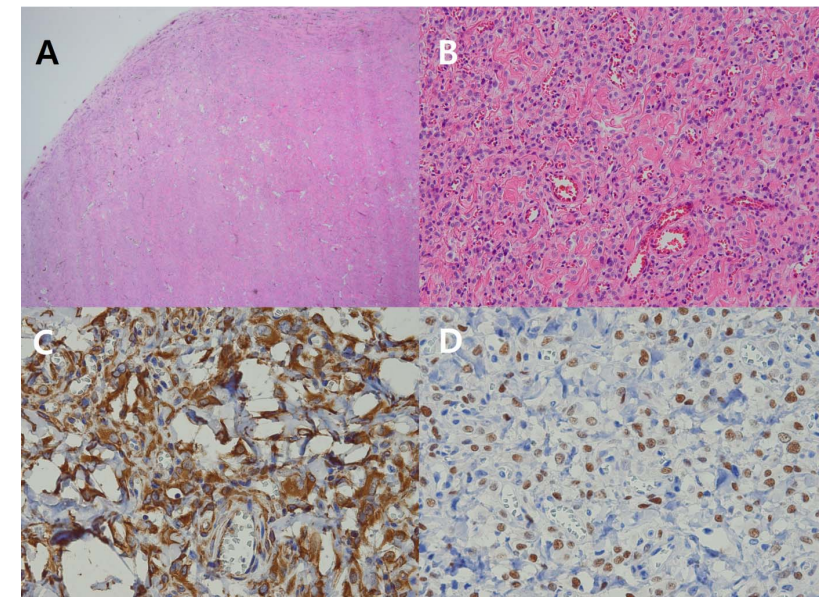

Figure 2. (A) The tumor mass showing well circumscribed border (hematoxylin-eosin, $\times 12.5$ ). (B) High cellularity of plump bland-looking stromal cells and abundance of blood vessels (hematoxylin-eosin, $\times 200$ ). (C) Diffuse strong positive finding of stromal cells in vimentin immunohistochemical stain $(\times 400)$. (D) Strong nuclear positive finding of stromal cells in estrogen receptor immunohistochemical stain $(\times 400)$.

52 who presented with slow growing mass. The longest diameter of the tumors ranged from 1.5 to $9 \mathrm{~cm}$. The most common site was vulva, followed by vaginal wall, uterine cervix. Two cases (Cases 8 and 13) were vaginal AMF that occurred after receiving adjuvant chemotherapy with tamoxifen for breast cancer.

AMF is an unusual kind of vulvar disease and commonly misdiagnosed as Bartholin cyst or lipoma. The size of the tumor is usually less than $5 \mathrm{~cm}$, but it was measured up to $23 \mathrm{~cm}$ in a report [2]. When the size of the tumor is big enough, it can be confused with perineal hernia. The tumor is usually asymptomatic and the patients often complain pelvic discomfort or cosmetic problem. Differential diagnosis of the vulvar mass includes other benign tumors such as cellular angiofibroma, fibroepithelial stromal polyp, or superficial angiomyxoma. These benign mesenchymal tumors are mostly found at vulvovaginal area and organize a distinctive disease entity [3].

The clinical diagnosis should be focused on differential diagnosis between AMF and AAM, because it determines the treatment options and prognosis. The treatment of AMF is complete excision and it does not require additional therapy. Although two of fourteen cases (Cases 4 and 12) have recurred each after 4 years and 8 years, they were treated in the same way. The treatment of recurred tumor was not different from primary one. In contrast, AAM is borderline and locally aggressive tumor. AAM is highly recurrent especially with improper resection so more aggressive surgery is needed [4]. The things that make treatment of AAM difficult are large size of the mass, infiltration to pelvic nerves or vessels, and recurrence even after complete resection [5]. Although wide surgical excision is the mainstay of treatment, incomplete resection can be rationalized regarding preservation of the pelvic organs [6]. Adjunctive therapy with GnRH agonist can be used after resection. The lesions of AAM are likely to be larger than other benign tumors, however the size does not support the diagnosis.

Imaging studies such as pelvic MRI or transperineal sonography can be helpful especially when the tumor size is large. They are performed preoperatively for two objectives: 1) to draw surgical resection margin and 2) for differential diagnosis. A CT scan can show infiltrative lesions of AAM and determine whether adjacent pelvic organs are intact. In addition, a perineal hernia can be identified on CT. For differential diagnosis, MRI or ultrasonography is superior to $\mathrm{CT}$ because radiologicpathologic correlation is more accurate. Gadoliniumenhanced T1 image is used in differentiating between $\mathrm{AAM}$ and $\mathrm{AMF}$, although $\mathrm{CT}$ findings of them are similar. Swirled intense pattern on MRI may represent thickeamned and hyalinized large vessels of AAM, whereas small capillaries of AMF show strong homogenous uptake [7]. The sonographic finding, mixed hyperechogenic and hypoechogenic areas, corresponds with alternating hypercellular and hypocellular pathology of AMF [8].

The histologic findings of AMF are similar but distinct from AAM. Grossly, AMF is well demarcated by a pseudocapsule and separated from surrounding tissue. Typical pathological findings are alternating hypercellular stromal area and hypocellular edematous area. Stromal cells are spindle or epitheloid shaped, are gathered around abundant capillary-type blood vessels. In contrast, AAM infiltrates to surrounding tissue and the border is not clear. The histology is characterized by abundant myxoid matrix, low cellularity, thickened medium-to-large size vessel, and extravasation of RBC [8]. Immunohistochemical stainings for vimentin, desmin, S-100, $\alpha$-SMA, CD34 and hormone receptors are usually performed (Table 2). The findings are helpful to diagnose; however it is not enough for differential diagnosis. The methods other than surgical excision such as needle biopsy or aspiration cytology are not sufficient to preoperative diagnosis. Simple microscopy with $\mathrm{H} \& \mathrm{E}$ stain remains as the standard tool [9]. The staining for estrogen and progesterone receptors shows hormone-dependent nature of these tumors.

One patient (Case 10) was lipomatous variant of AMF. Adipose compound is frequently found in ordinary AMF and subcutaneous fat is thought to be entrapped as the tumor grows. However, the case is called lipomatous variant bacause adipose tissue takes up the integral part of the tumor [10]. The adipocytes of lipomatous variant 
Table 1. Clinical findings of 14 patients in Korea with angiomyofibroblastoma.

\begin{tabular}{|c|c|c|c|c|c|c|c|c|}
\hline Case & Authors & Age & Site & Clinical diagnosis & Operation & Size $(\mathbf{c m})$ & Duration & Follow up \\
\hline 1 & Lee (1995) & 46 & Vulva & Benign tumor & Excision & $7 \times 5 \times 3.5$ & 1 year & ${ }^{\mathrm{a}} \mathrm{INA}$ \\
\hline 2 & Park (1996) & 34 & Right vulva & Lipoma & Excision & $4 \times 2.5$ & 1 year & INA \\
\hline 3 & Roh (1996) & 45 & Left vulva & Benign tumor or inguinal hernia & Excision & $4.5 \times 4.2$ & 3 months & INA \\
\hline 4 & Park (1996) & 45 & Right labium major & Aggressive angiomyxoma & Excision & $1.5 \times 1.0 \times 0.4$ & 2 months & INA \\
\hline 5 & Lee (1997) & 42 & Left vulva & Bartholin cyst or lipoma & Marsupialization & $3 \times 1.5 \times 0.9$ & 2 months & ${ }^{b} \mathrm{NED}$ \\
\hline 6 & Jo (2003) & 52 & Left labium major & Benign tumor & Excision & $4 \times 5$ & 2 years & NED \\
\hline 7 & Jeong (2003) & 21 & Right vaginal wall & Vaginal tumor & Excision & $8.6 \times 5 \times 3$ & 3 month & NED \\
\hline 8 & Bae (2005) & 50 & Left vaginal wall & Benign tumor & Excision & 2 & $\begin{array}{l}\text { Incidentally } \\
\text { found }\end{array}$ & NED \\
\hline 9 & $\operatorname{Lim}(2008)$ & 48 & Anterior vaginal wall & $\begin{array}{l}\text { Leiomyoma, neurilemmoma, } \\
\text { or soft tissue sarcoma }\end{array}$ & Excision & $3.8 \times 3.5 \times 2.8$ & $\begin{array}{l}\text { Incidentally } \\
\text { found }\end{array}$ & INA \\
\hline 10 & Kim (2009) & 40 & Vulva & $\begin{array}{l}\text { Myxoid tumor or leiomyoma } \\
\text { with myxoid degeneration }\end{array}$ & Excision & $9.0 \times 5.5 \times 2.5$ & 3 years & INA \\
\hline 11 & Lee (2010) & 46 & Left vulva & Bartholin cyst or lipoma & Excision & $4 \times 3 \times 2$ & 2 years & NED \\
\hline 12 & Lee (2011) & 31 & Left vulva & Angiomyofibroblastoma & Excision & $4.5 \times 1.4$ & 1 month & INA \\
\hline 13 & $\operatorname{Kim}(2011)$ & 43 & Uterine cervix & Cervical myoma & Excision & $3 \times 3 \times 2.5$ & $\begin{array}{l}\text { Incidentally } \\
\text { found }\end{array}$ & INA \\
\hline $14^{*}$ & Park (2013) & 51 & Right vulva & Cystic mass & Excision & $2.5 \times 1.5 \times 0.8$ & 1 year & NED \\
\hline
\end{tabular}

${ }^{\text {Present case; }}{ }^{\mathrm{a}}$ INA : Information not available; ${ }^{\mathrm{b}} \mathrm{NED}$ : No evidence of disease.

Table 2. Immunohistochemical profiles of 14 cases in Korea.

\begin{tabular}{|c|c|c|c|c|c|c|c|c|}
\hline Case & Vimentin & Desmin & MSA & S-100 & $\alpha$-SMA & CK & CD34 & ER/PR \\
\hline 1 & + & + & + & \pm & $\mathrm{U}$ & $\mathrm{U}$ & $\mathrm{U}$ & $\mathrm{U}$ \\
\hline 2 & + & + & - & - & - & $\mathrm{U}$ & $\mathrm{U}$ & $\mathrm{U}$ \\
\hline 3 & + & + & $\mathrm{U}$ & - & $\mathrm{U}$ & - & $\mathrm{U}$ & $\mathrm{U}$ \\
\hline 4 & + & + & $\mathrm{U}$ & - & - & $\mathrm{U}$ & $\mathrm{U}$ & $\mathrm{U}$ \\
\hline 5 & + & + & - & $\mathrm{U}$ & - & $\mathrm{U}$ & $\mathrm{U}$ & $\mathrm{U}$ \\
\hline 6 & + & \pm & $\mathrm{U}$ & $\mathrm{U}$ & $\mathrm{U}$ & $\mathrm{U}$ & $\mathrm{U}$ & $\mathrm{U}$ \\
\hline 7 & + & + & - & - & - & $\mathrm{U}$ & $\mathrm{U}$ & $\mathrm{U}$ \\
\hline 8 & $\mathrm{U}$ & + & $\mathrm{U}$ & $\mathrm{U}$ & $\mathrm{U}$ & $\mathrm{U}$ & + & $\mathrm{U}$ \\
\hline 9 & $\mathrm{U}$ & U & U & $\mathrm{U}$ & $\mathrm{U}$ & $\mathrm{U}$ & $\mathrm{U}$ & $\mathrm{U}$ \\
\hline 10 & $\mathrm{U}$ & + & $\mathrm{U}$ & + & - & - & $\mathrm{U}$ & + \\
\hline 11 & + & - & $\mathrm{U}$ & $\mathrm{U}$ & $\mathrm{U}$ & $\mathrm{U}$ & $\mathrm{U}$ & + \\
\hline 12 & $\mathrm{U}$ & + & U & $\mathrm{U}$ & - & $\mathrm{U}$ & $\mathrm{U}$ & + \\
\hline 13 & + & + & $\mathrm{U}$ & $\mathrm{U}$ & - & U & - & + \\
\hline 14 & + & $\mathrm{U}$ & $\mathrm{U}$ & $\mathrm{U}$ & $\mathrm{U}$ & $\mathrm{U}$ & $\mathrm{U}$ & + \\
\hline Total & $10 / 10$ & $10 / 12$ & $1 / 4$ & $2 / 5$ & $0 / 7$ & $0 / 2$ & $1 / 2$ & $5 / 5$ \\
\hline
\end{tabular}

$+=$ Positive, $\pm=$ Weak positive, $-=$ Negative, $\mathrm{U}=$ Unknown, MSA $=$ Muscle specific actin, $\alpha$-SMA $=$ Alpha smooth muscle actin, $\mathrm{CK}=\mathrm{Cy}-$ tokeratin, $\mathrm{ER}=$ Estrogen receptor, $\mathrm{PR}=$ Progesterone receptor. have nuclei similar to stromal cells and are thought to be neoplastic origin. The HMGA2 gene arrangement which is a common genetic abnormality of lipoma may be responsible for the fatty differentiation [11].

$\mathrm{AMF}$ and AAM are thought to be originated from myofibroblastic or fibroblastic cells, although it is still debatable whether both belong to a same disease spectrum. AMF and other mesenchymal tumors that occur exclusively in the vulva seem to be from common progenitor, CD34 positive perivascular stem cells [10]. Similar immunochemistry patterns for vimentin and desmin suggest their myofibroblastic origin. A morphological overlap between AAM and AMF was reported, suggesting the possibility that common origin could exist. Conversely, a recent molecular study supports the hypothesis that AAM and AMF are biologically distinct neoplasms. The HMGA2 gene arrangement is found in $1 / 3$ of AAM but not in AMF. However, this finding is of limited value due to the low sensitivity of the gene arrangement [11].

In conclusion, AMF is a benign tumor, both clinically and pathologically. The tumor is presumed benign and the operation is performed. Although accurate diagnosis is not probable, AAM should be ruled out before the surgery considering the diagnosis is usually based on clinical context. It is helpful for differential diagnosis to use image modalities such as pelvic sonography, CT or 
MRI.

\section{CONCLUSION}

In conclusion, AMF is a benign tumor, both clinically and pathologically. The tumor is presumed benign and the operation is performed. Although accurate diagnosis is not probable, AAM should be ruled out before the surgery considering the diagnosis is usually based on clinical context. It is helpful for differential diagnosis to use image modalities such as pelvic sonography, CT or MRI.

\section{REFERENCES}

[1] Fletcher, C.D., Tsang, W.Y., Fisher, C., Lee, K.C. and Chan, J.K. (1992) Angiomyofibroblastoma of the vulva. A benign neoplasm distinct from aggressive angiomyxoma. The American Journal of Surgical Pathology, 16, 373-382. doi:10.1097/00000478-199204000-00006

[2] Kimihiro, N., Koji, A. and Hitoaki, S. (2010) Huge pedunculated angiomyofibroblastoma of the vulva. International Journal of Clinical Oncology, 15, 201-205. doi:10.1007/s10147-010-0026-0

[3] Magro, G., Caltabiano, R., Kacerovská, D., Vecchio, G.M., Kazakov, D. and Michal, M. (2012) Vulvovaginal myofibroblastoma: Expanding the morphological and immunohistochemical spectrum. A clinicopathologic study of 10 cases. Human Pathology, 43, 243-253. doi:10.1016/j.humpath.2011.04.027

[4] Amezcua, C.A., Begley, S.J., Mata, N., Felix, J.C. and Ballard, C.A. (2005) Aggressive angiomyxoma of the female genital tract: A clinicopathologic and immunohistochemical study of 12 cases. International Journal of Gynecological Cancer, 15, 140-145. doi:10.1111/j.1048-891x.2005.15015.x
[5] Magtibay, P.M., Salmon, Z., Keeney, G.L. and Podratz, K.C. (2006) Aggressive angiomyxoma of the female pelvis and perineum: A case series. International Journal of Gynecological Cancer, 16, 396-401. doi:10.1111/j.1525-1438.2006.00225.x

[6] Chan, Y.M., Hon, E., Ngai, S.W., Ng, T.Y. and Wong, L.C. (2000) Aggressive angiomyxoma in females: Is radical resection the only option? Acta Obstetricia et Gynecologica Scandinavica, 79, 216-220. doi:10.1080/j.1600-0412.2000.079003216.x

[7] Mortele, K.J., Lauwers, G.J., Mergo, P.J. and Ros, P.R. (1999) Perineal angiomyofibroblastoma: CT and MR findings with pathologic correlation. Journal of Computer Assisted Tomography, 23, 687-689. doi:10.1097/00004728-199909000-00007

[8] Kim, S.W., Lee, J.H., Han, J.K. and Jeon, S. (2009) Angiomyofibroblastoma of the vulva: Sonographic and computed tomographic findings with pathologic correlation. Journal of Ultrasound in Medicine, 28, 1417-1420.

[9] Granter, S.R., Nucci, M.R. and Fletcher, C.D. (1997) Aggressive angiomyxoma: Reappraisal of its relationship to angiomyofibroblastoma in a series of 16 cases. Histopathology, 30, 3-10. doi:10.1046/j.1365-2559.1997.d01-556.x

[10] Laskin, W.B., Fetsch, J.F. and Mostofi, F.K. (1998) Angiomyofibroblastomalike tumor of the male genital tract: analysis of 11 cases with comparison to female angiomyofibroblastoma and spindle cell lipoma. The American Journal of Surgical Pathology, 22, 6-16. doi:10.1097/00000478-199801000-00002

[11] Medeiros, F., Erickson-Johnson, M.R., Keeney, G.L., Clayton, A.C., Nascimento, A.G., Wang, X. and Oliveira, A.M. (2007) Frequency and characterization of HMGA2 and HMGA1 rearrangements in mesenchymal tumors of the lower genital tract. Genes Chromosomes Cancer, 46, 981-990. doi:10.1002/gcc.20483

\section{ABBREVIATION}

AMF: angiomyofibroblastoma;

AAM: aggressive angiomyxoma 